\title{
(6) OPEN ACCESS \\ An evaluation of the FDA's analysis of the costs and benefits of the graphic warning label regulation
}

\author{
Frank J Chaloupka, ${ }^{1}$ Kenneth E Warner, ${ }^{2}$ Daron Acemoğlu, ${ }^{3}$ Jonathan Gruber, ${ }^{3}$ \\ Fritz Laux, ${ }^{4}$ Wendy Max ${ }_{1}^{5}$ Joseph Newhouse, ${ }^{6}$ Thomas Schelling, ${ }^{7}$ Jody Sindelar ${ }^{8}$
}

For numbered affiliations see end of article.

\section{Correspondence to}

Professor Frank J Chaloupka, Department of Economics, Institute for Health Research and Policy, University of Illinois at Chicago, Chicago, IL 60608 USA:

fjc@uic.edu

Received 1 October 2014 Accepted 28 November 2014 Published Online First 30 December 2014

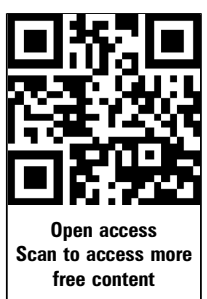

\section{SLinked}

- http://dx.doi.org/10.1136/ tobaccocontrol-2014-052095 - http://dx.doi.org/10.1136/ tobaccocontrol-2014-052100

\section{CrossMark}

To cite: Chaloupka FJ, Warner KE, Acemoğlu D, et al. Tob Control 2015:24:112-119.

\section{ABSTRACT}

The Family Smoking Prevention and Tobacco Control Act of 2009 gave the Food and Drug Administration (FDA) regulatory authority over cigarettes and smokeless tobacco products and authorised it to assert jurisdiction over other tobacco products. As with other Federal agencies, FDA is required to assess the costs and benefits of its significant regulatory actions. To date, FDA has issued economic impact analyses of one proposed and one final rule requiring graphic warning labels (GWLs) on cigarette packaging and, most recently, of a proposed rule that would assert FDA's authority over tobacco products other than cigarettes and smokeless tobacco. Given the controversy over the FDA's approach to assessing net economic benefits in its proposed and final rules on GWLs and the importance of having economic impact analyses prepared in accordance with sound economic analysis, a group of prominent economists met in early 2014 to review that approach and, where indicated, to offer suggestions for an improved analysis. We concluded that the analysis of the impact of GWLs on smoking substantially underestimated the benefits and overestimated the costs, leading the FDA to substantially underestimate the net benefits of the GWLs. We hope that the FDA will find our evaluation useful in subsequent analyses, not only of GWLs but also of other regulations regarding tobacco products. Most of what we discuss applies to all instances of evaluating the costs and benefits of tobacco product regulation and, we believe, should be considered in FDA's future analyses of proposed rules.

\section{INTRODUCTION}

As part of the rule-making process, Federal government agencies are required to conduct an economic impact analysis of 'significant' proposed and final rules (ie, those with an annual effect on the economy of $\$ 100$ million or more), assessing all costs and benefits associated with a given regulation. ${ }^{12}$ Pursuant to this Executive Order, the Food and Drug Administration (FDA) is required to prepare an economic impact analysis of proposed and final rules issued under the authority assigned to the agency by the 2009 Family Smoking Prevention and Tobacco Control Act (FSPTCA). The act gave FDA jurisdiction to regulate cigarettes and smokeless tobacco products and authorised it to assert jurisdiction over other tobacco products by issuing a rule. To date, the FDA has issued one proposed and final rule requiring graphic warning labels (GWLs) on cigarette packaging (hereafter the GWL rule) for which such an analysis was required. ${ }^{3}{ }^{4}$ In April 2014, the FDA issued a proposed rule that would assert the FDA's authority over other tobacco products and issued an economic impact analysis with regard to the rule. ${ }^{5}$

There are essentially three steps in conducting this type of economic impact analysis for FDA rules affecting tobacco products: estimating the impact of alternative regulations on tobacco use, assessing the economic benefits of these reductions in tobacco use, and determining the economic costs of implementing these regulations. Clearly, the magnitude of the estimates from each step will have a significant impact on the final estimate of the net benefits or costs of alternative regulations. The assumptions made at each step will also have important implications for estimating the net economic impact. Applying assumptions from traditional economic theory, while reasonable when assessing the economic impact of regulations on many consumer goods, can result in grossly distorted estimates of benefits and costs when applied to the analysis of tobacco products, given the market failures caused by addiction and imperfect and asymmetric information that are exacerbated by initiation of product use, for most, during adolescence.

How best to conduct this type of regulatory impact analysis for tobacco products is controversial, as illustrated by the range of comments on the analyses included in the proposed GWL rule, and subsequent publications discussing the approach used in the final rule. At one end of the spectrum are those supporting the application of conventional economic theory and measurement, incorporating some of the advances made in recent years for the economic analysis of addictive behaviours. ${ }^{6}$ On the other end are those arguing that the rational choice framework of economics is inappropriate for the analysis of the net impact of regulations on tobacco use, given the evidence that tobacco use is an irrational behaviour. ${ }^{7}$

In an effort to inform this analytic process, a group of prominent economists met in early 2014 to review the approach used by the FDA in its economic impact analysis for the proposed and final GWL rules. This paper summarises the consensus of this group with respect to key assumptions and considerations for conducting this type of analysis within the framework of economic theory. Within this discussion, our theoretical attention focuses on the most contentious issue-how to measure the reductions in consumer surplus (the 'pleasure' that smokers receive from smoking, measured by the difference between their willingness to pay for cigarettes and the actual price they pay) resulting from reductions in smoking in response to GWLs. While the GWL rules motivated our analysis, most 
of what we discuss applies to all instances of evaluating the costs and benefits of tobacco product regulation.

\section{ESTIMATING THE IMPACT OF REGULATORY ACTIONS ON TOBACCO USE}

Comparing trends in adult smoking prevalence in Canada and the USA from 1991 until 2009, the FDA estimated that the implementation of GWLs in the USA would reduce smoking prevalence by 0.088 percentage points, or just over $0.4 \%$, resulting in 213000 fewer smokers in 2013 and growing to about 246000 by 2031, given the increases in population over time. The FDA's approach accounted for the underlying trends in cigarette smoking in the two countries prior to the implementation of GWLs in Canada in mid-2001, as well as the effects of inflation adjusted cigarette taxes in the two countries. Using estimates from this model, FDA projected Canadian smoking prevalence rates from 2001 until 2009, and attributed the difference between the projected rates and the actual rates to the GWLs.

Recent research, not available to the FDA at the time of its analysis, indicates that the $0.4 \%$ reduction estimated by the FDA significantly understates the impact of GWLs on adult cigarette smoking prevalence. For example, using nationally representative data on smoking among persons 15 years and older from the Canadian National Population Health Surveys conducted from 1998 until 2008, Azagba and Sharaf estimate that smoking prevalence in Canada fell by $12.5 \%$ as a result of that country's GWLs, ${ }^{8}$ nearly 30 times as large a reduction as that estimated by the FDA. Importantly, Azagba and Sharaf ${ }^{8}$ controlled for other key tobacco control policies, including cigarette prices and smoke-free policies, as well as a variety of individual characteristics. In addition to their findings for smoking prevalence, Azagba and Sharaf ${ }^{8}$ also find that the GWLs reduced the prevalence of daily smoking, while significantly increasing quit attempts among smokers.

Huang et $a l^{9}$ produce similar estimates in their reanalysis of the data used by FDA, concluding that the GWLs reduced smoking prevalence by between $12.1 \%$ and $19.6 \%$ in Canada, implying that implementation of GWLs in the USA would lead to at least 5.3 million fewer smokers. The difference between Huang et al's estimates and those produced by the FDA largely result from two differences in their approaches. First, Huang et $a l^{9}$ estimated a difference-in-difference model that pooled the Canadian and US data for the full 1991-2009 period, and estimated a statistically significant, negative effect of the GWLs on smoking prevalence. Second, rather than using inflation-adjusted cigarette taxes in their analysis, as was done by the FDA, Huang et $a l^{9}$ used a measure of actual cigarette prices that accounted for the ready availability of illicit cigarettes in Canada during the post-GWL implementation period. The latter adjustment is particularly important given that, while inflation-adjusted cigarette taxes and official measures of prices rose in both countries from 2001 until 2009, the inflation-adjusted prices paid by smokers actually fell in Canada, while increasing in the USA. Specifically, taxes and official prices rose by $123 \%$ and $64 \%$, respectively, in Canada, and by $117 \%$ and $42 \%$, respectively, in the USA, while the actual prices paid by smokers fell by $4 \%$ in Canada and rose by $25 \%$ in the USA. As Huang $e t a l^{9}$ note, the differences between the official price measures and those based on the prices that smokers report paying are most likely largely explained by cigarette smuggling, which grew sharply for most of this period, accounting for as much as one quarter of Canadian cigarette consumption in 2008, in contrast to the relatively stable share of the US market accounted for by smuggled cigarettes, which reached a high of $6 \%$ in 2009 in the USA.

The consensus of our group, given the more recent research, is that the initial step in the FDA's regulatory impact analysis of GWLs almost certainly resulted in a considerable underestimate of the impact of GWLs on the number of smokers in the USA. Since this estimate drives the subsequent estimates of the benefits and costs of the GWLs, the estimated net benefit produced in the FDA's final rule was also almost certainly significantly underestimated. While this particular error is specific to the analysis of GWLs, it highlights how failing to incorporate the unique aspects of tobacco use and tobacco control can produce biased estimates, a problem that may reappear in future regulatory impact analyses. We encourage the FDA to conduct more nuanced analyses of the impact of future regulatory actions on tobacco use that account, to the extent possible, for the factors that differentiate tobacco markets from those of most other consumer products.

\section{ESTIMATING THE BENEFITS OF REDUCTIONS IN TOBACCO USE}

Once the reductions in tobacco use caused by regulatory actions have been estimated, the second step in the economic impact assessment is to quantify the benefits that result from lower tobacco use. In its final GWL rule, the FDA concluded that the largest benefits will be those that result from reductions in death and disease caused by tobacco use, consisting of reductions in cardiovascular diseases, cancers, respiratory diseases and the other disease consequences of smoking. In its efforts to quantify these benefits, the FDA omitted several significant benefits, while making questionable assumptions that most likely lead to a substantial underestimate of the actual benefits for those that were included.

One major omission is the reductions in non-smokers' exposure to tobacco smoke that accompany the reductions in smoking in response to GWLs. As is well documented in the 50th anniversary report of the Surgeon General, exposure to tobacco smoke causes lung cancer, coronary heart disease, stroke and other diseases in adults, and middle ear disease, impaired lung function, and respiratory illness, including bronchitis and pneumonia, in children, and sudden infant death syndrome in newborns. ${ }^{10}$ From 2005 until 2009, secondhand smoke exposure is estimated to have caused over 41000 deaths annually, more than $8.5 \%$ of all deaths attributable to smoking. Assuming that GWLs reduce adult smoking prevalence by $12.1 \%$, the lower end of the range estimated by Huang et al, ${ }^{9}$ and that reductions in deaths from secondhand smoke exposure are proportional to reductions in smoking prevalence, GWLs would result in nearly 5000 fewer deaths annually among non-smokers. Assuming the same average value of lost productivity as estimated for smokers dying prematurely from a smoking-attributable disease, the equivalent reduction in lost productivity for non-smokers would be at least $\$ 1.7$ billion. This is only a fraction of the benefits that would accrue to non-smokers as a result of reductions in smoking, given that it does not include the reductions in healthcare spending to treat the diseases caused by exposure to tobacco smoke, the impact on infants, children and adolescents and the value of the more difficult to quantify reductions in the irritation and other factors caused by secondhand smoke exposure. In theory, all of these should be included in the analysis.

Similarly omitted from the FDA's GWL impact analysis are the benefits that result from reductions in maternal smoking during pregnancy. The epidemiological evidence clearly 
demonstrates that smoking during pregnancy causes a number of complications, including low birth weight, ectopic pregnancy, spontaneous abortion, stillbirth, premature birth and more, as well as consequences after birth, from increased risk of sudden infant death syndrome and asthma to developmental problems, learning disorders and other lasting consequences. ${ }^{10}{ }^{11}$ The healthcare costs of pregnancies and births complicated by smoking can be considerable, while the lifetime costs that result from fetal exposure to maternal smoking are likely to be very large. Failing to include the reductions in these costs following implementation of the regulatory actions that the FDA can take will again lead to a significant underestimate of the benefits of those actions.

Another key omission in the FDA assessment of benefits is the reduction in the costs of a variety of healthcare services used to treat the diseases caused by smoking. In its final GWL rule, the FDA's estimates of reductions in the costs of medical services were based on work by Sloan et al, ${ }^{12}$ which included hospitalisations, physician visits and nursing home use. Other healthcare costs, including the costs of medications, home healthcare and other types of outpatient care, are not included, as well as the costs of nursing home care necessitated by the smoking-related illness of a smoker's caregiver. Likewise, while reductions in some of the costs of fires attributable to smoking were included in the FDA's analysis, others were not, most notably the reduction in the costs of injuries requiring medical attention resulting from smoking-attributable fires. Smoking is the single most important cause of fires and burn injuries. Finally, the FDA's analysis did not include the benefits resulting from reduced smoking in response to GWLs by smokers who continue to smoke. While GWLs would induce many smokers to quit, many others who are unable to quit will reduce the number of cigarettes they smoke each day and/or reduce the number of days they smoke. Although smaller than those that result from quitting entirely, the health consequences of these reductions will generate additional benefits given the positive impact of reduced smoking on health (for the smoker and others) and the related reductions in smoking-attributable morbidity and mortality.

Similarly, assumptions about how the benefits are distributed over time can have a considerable impact on the present value of these benefits, given that future benefits are discounted heavily. The distribution of benefits should derive from empirical evidence. In its economic impact analysis of the GWL rule, the FDA assumed that reductions in healthcare spending were spread out equally over time, apparently ignoring evidence that many of the benefits of quitting occur almost immediately. For example, there are immediate reductions in the risks of a heart attack or stroke after quitting, and most of the excess risk is gone within 1-5 years. Spreading the reduction in all benefits out evenly over time is likely to misrepresent the true present value of the benefits from reductions in many of the most common consequences of smoking.

The FDA's analysis appropriately accounts for the fact that smokers differ from never-smokers in many ways, including income levels, insurance status, race and ethnicity, and participation in other risky behaviours. This implies that these differences need to be accounted for when estimating the healthcare costs of smoking, something commonly done by estimating costs for the counterfactual 'non-smoking smoker', with the difference in costs between the smoker and the non-smoking smoker reflecting the excess costs caused by smoking. However, the FDA's approach, following that used by Sloan et al, ${ }^{12}$ compared costs for smokers to costs for hypothetical non-smoking smokers, comprised of never-smokers and former smokers, rather than comparing costs for smokers to hypothetical neversmoking smokers. Given that the difference in expenditures for smokers and non-smokers will be smaller than that for smokers and never-smokers, this approach will lead to an underestimate of the benefits resulting from reduced initiation of smoking in response to the FDA regulatory actions.

Given these and additional issues, noted briefly below, the consensus of the group was that the FDA's approach to estimating the benefits of its regulatory actions could be significantly improved. Going forward, we recommend several refinements to the FDA's approach. First are points addressed above. Following them are a number of additional refinements we have not discussed above.

As discussed above, we recommend:

- Inclusion of the benefits to non-smokers that result from reductions in smoking caused by the FDA's regulatory actions, most notably the reduction in the health consequences of secondhand smoke exposure by non-smokers.

- Similarly, inclusion of the short-term and long-term benefits associated with reduced maternal smoking during pregnancy.

- Inclusion of a more comprehensive set of healthcare services, given the omission of medication home healthcare services, and other outpatient care from the final rule on GWLs. Injury costs averted by the reduction in smoking-produced fires should be included as well.

- Inclusion of the benefits for smokers and those around them of GWL-induced reductions in smoking by smokers who do not quit.

- Modelling of the health impact of changes in smoking that better accounts for the short-term benefits that result from reductions in use, particularly the immediate benefits from reduced risks of heart attack and stroke, as well as those resulting from reductions in tobacco use during pregnancy. This will lead to a very different pattern of benefits than that used in the final GWL rule that spread these out evenly over time. This is a problem compounded by discounting benefits over an exceedingly long time horizon of over 80 years for young tobacco users.

Additional refinements to the FDA's approach to assessing benefits, not discussed above, include:

- Inclusion of more detailed measures of smoking in special subpopulations given that FDA regulations can differentially impact different population groups. For example, GWLs that target specific populations, such as pregnant women or adolescents, could have a larger impact on these populations. Similarly, regulations related to menthol would be likely to have a greater impact on tobacco use among African Americans and young people, who smoke menthol cigarettes in far greater proportions than do other smokers.

- Inclusion of the costs avoided that are associated with the use of other tobacco products and dual use of such products with cigarette smoking. While estimates of the lost productivity and increased medical care costs of cigarette smoking are available, comparable estimates for the costs of other tobacco product use and multiproduct use have not been developed, despite the existence of data that would allow such estimation, at least for products that have been in use for many years. Over time, as similar data become available for the use of new and emerging nicotine and tobacco products, including electronic nicotine delivery systems, the costs of their use should also be incorporated.

- Updating of the estimates of the lifetime costs of tobacco use given that the estimates relied on by the FDA are based on analyses of data that are more than a decade or two old. 
Since these data were collected, there have been important changes in smoking behaviour and other tobacco product use.

These enhancements to the approach used by the FDA will lead to a more comprehensive measure of the benefits of its future regulatory actions on tobacco products. In the specific instance of the GWL rulings, and in other FDA proposed regulations in the future, inclusion of these benefits will substantially increase the FDA's estimate of the benefits associated with improved health as a result of the regulations.

\section{ESTIMATING THE COSTS OF REGULATORY ACTIONS}

The final step in calculating the net economic impact of the FDA's regulatory actions is to assess the implementation costs. In its proposed and final rules to date, these costs consist of three key components: the costs to the industry of implementing the regulations, the FDA's administrative and enforcement costs and the costs to smokers. Estimating the industry costs is relatively straightforward. In the case of the GWL rule, these costs include the costs of changing cigarette labels, discarding noncompliant labels, market testing of changing labels and removing non-compliant point-of-sale advertising. Similarly, estimating the FDA's costs for administering and enforcing the rule is also relatively straightforward. In the final GWL rule, the estimates of the combined industry and government costs ranged from $\$ 319.5$ to $\$ 518.4$ million for the one-time fixed costs of implementing the new labels and from $\$ 6.6$ to $\$ 7.1$ million in annual implementation and enforcement costs. ${ }^{4}$ These costs are far below the estimated benefits. Stopping the GWL analysis at this point would have implied a significant net economic benefit from the implementation of the GWL rule, despite the almost certain substantial underestimation of the reductions in smoking that would have resulted from the new labels and of the benefits that would accrue. Assuming larger GWL-induced reductions in smoking, as estimated in recent papers, ${ }^{8} 9$ would produce enormous net benefits, given that the costs to the industry and government are largely independent of changes in smoking, while the benefits are proportional to reductions in prevalence.

The FDA analysis, however, did not stop at this point, but instead included the potential cost to smokers of the reductions in smoking caused by the GWLs-what economists refer to as lost consumer surplus. For fully-informed, rational consumers, consumer surplus reflects the difference between their willingness to pay for a product and the actual price they pay in the marketplace; graphically, this is the area under the demand curve but above the market price, as shown in figure 1A. Regulatory actions that reduce the demand for a product (as shown in figure 1B) or that raise its market price (as shown in figure 1C) will lead to reductions in consumer surplus, reflecting the lost satisfaction that results from reduced consumption. In the FDA's economic impact analysis of its GWL rule, it applied this standard tool of welfare economics to cigarette smoking and reduced the benefits resulting from reductions in smoking caused by the labels by roughly half in order to account for the lost consumer surplus.

In one extreme model in which consumers are making fully informed, perfectly rational and forward-looking choices, consumers induced to quit by GWLs would indeed lose consumer surplus. Without knowing the exact demand function, this surplus could be much smaller or much greater than half of the health benefits. However-and this is a key point-in this model, there would be no reason for the smoker to quit in response to the GWL. This is a crucial point-the very fact that the GWL has a strong impact on quitting, as documented by the evidence cited above, contradicts the very use of this extreme model.

At the other extreme, in a model in which all consumers are making irrational decisions either when taking up smoking or while deciding whether and when to quit, the concept of consumer surplus loses its normative appeal. If, for example, all smokers are addicted and suffer the disutility of wanting but being unable to quit, their persistent smoking has no implications for the amount of pleasure they receive from continued smoking. Once again, however, in such a model GWL would not cause quitting among these addicted smokers.

While neither of these extreme models is completely correct when applied to smoking, the available evidence suggests that the latter is likely to be closer to reality than the former. As the FDA's analysis observes, smoking prevalence is well above the level that would result from forward-looking, time consistent decisions made by individuals who are fully informed about the health consequences of smoking, including addiction and who appropriately internalise this information. Instead, most smoking initiation takes place during adolescence or young adulthood among individuals who are often less than fully aware of the health and economic consequences of smoking, have little to no conception of their own mortality, heavily discount future consequences, and, perhaps most importantly, do not fully understand addiction. As noted above, few youth who are smoking as high school seniors expect to be smoking 5 years later, but most continue to do so. Data from the Monitoring the Future Surveys, for example, show that while only $3 \%$ of those smoking daily as high school seniors thought that they would definitely be smoking in 5 years, almost two-thirds were still smoking 7-9 years later. ${ }^{13}$

Once smokers begin smoking, extensive behavioural, economic and psychological research shows that their decisions to continue to smoke are time inconsistent, satisfying their shortrun desire for immediate gratification rather than their long-run desire for good health, then later regretting these decisions. Data from the 2002 wave of the International Tobacco Control Policy Evaluation Project (ITC)-US Survey show that more than 9 of 10 smokers agreed or strongly agreed with the statement "If you had to do it over again, you would not have started smoking". ${ }^{14}$ Similarly, the U.S. Centers for Disease Control and Prevention (CDC) reports that in 2010, nearly 7 of every 10 smokers reported that they wanted to quit smoking completely and more than half of all smokers stopped smoking for at least 1 day because they were trying to quit smoking. ${ }^{15}$ Yet only $2.7 \%$ of smokers quit each year. ${ }^{16}$

These data strongly suggest that many, and most likely the vast majority, of the smokers do not find smoking 'pleasurable' and derive little 'consumer surplus' from smoking. Instead, most continuing smokers avoid the withdrawal symptoms they would experience if they were able to stop smoking and break the addiction that most regret having ever started. Indeed, Gruber and Mullainathan ${ }^{17}$ find that the self-reported happiness of potential smokers rises when cigarette taxes are increased. This is consistent with quitting causing an increase, rather than a reduction, in consumer surplus. Note that smoking literally rewires the brain, ${ }^{18}$ a phenomenon not familiar to many economists but indicative of a biological barrier to smokers exerting the self-control that is essential in the model of rational consumer behaviour.

In discussing the issue of how to treat lost consumer surplus in this type of economic impact analysis, we decided that it was most informative to separate smokers into those who became regular smokers before the legal age of smoking, and those who 


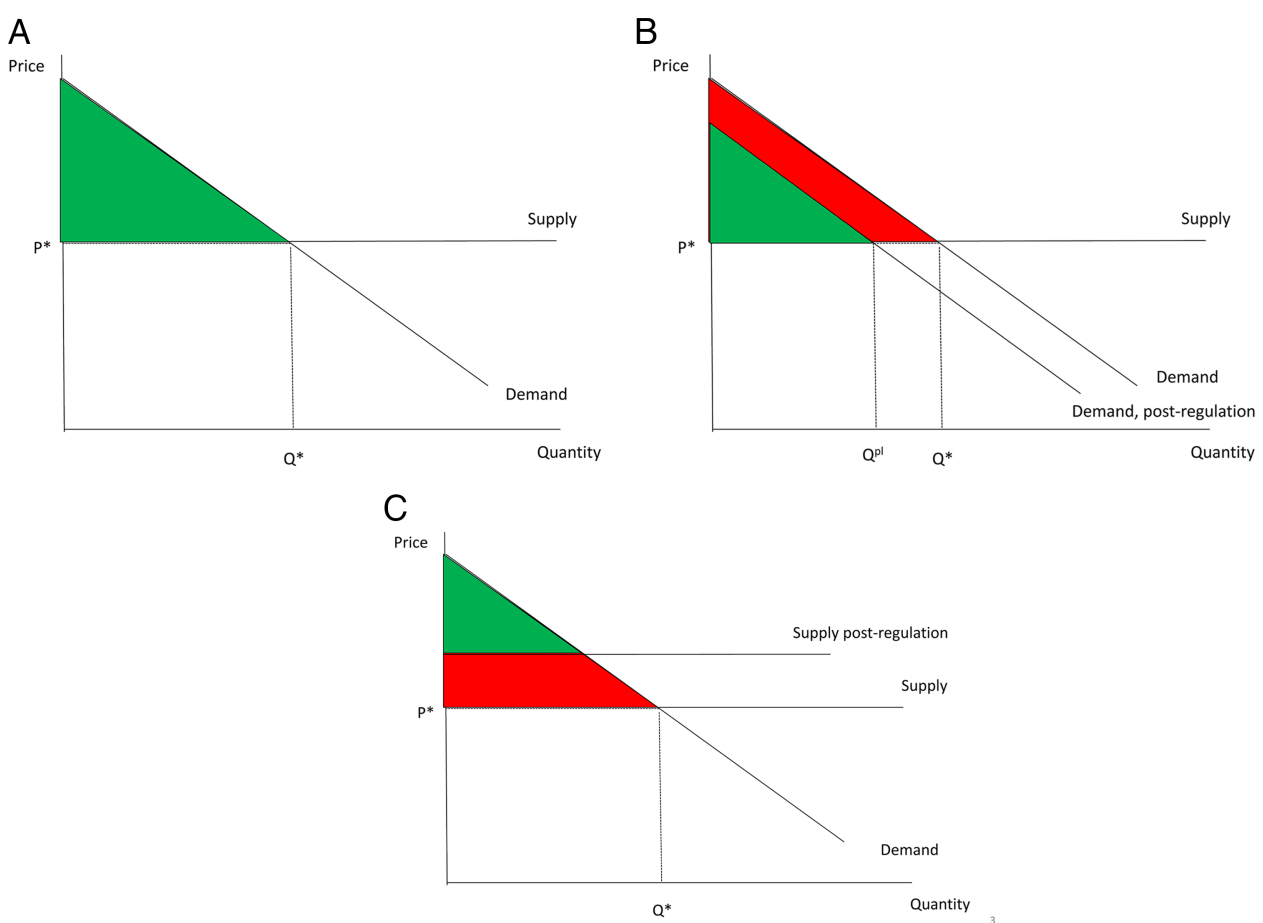

Figure 1 (A) The area under the demand curve but above the market price. (B) Regulatory actions that reduce the demand for a product. (C) Regulatory actions that raise the market price of a product.

become regular smokers thereafter. For the former group, society has clearly decided that the decision to initiate smoking is an irrational decision and any changes in their conventionally calculated consumer surplus resulting from changes in their tobacco use in response to GWLs or other actions should not be counted as a cost in the economic impact analysis of the FDA's rules on tobacco. This is illustrated by laws regulating youth access to tobacco products, including the FDA enforcement of a national legal purchase age of 18 for tobacco products over which it has jurisdiction. We refer to this as the 'principle of insufficient reason' approach and argue that the benefits to those who started using tobacco products regularly before 18 years of age and who quit in response to FDA regulatory actions should not have any offset for lost consumer surplus. Some small fraction of those smokers made what might be interpreted as a rational decision and their lost consumer surplus could be included. This might be set at $8.8 \%$, given the ITC survey finding that $91.2 \%$ of adult smokers in the USA say that they would never have started smoking if they had to do it all over again.

One difficulty with this approach is that we need to distinguish those who became regular smokers as minors from those who became regular smokers as adults. For those who smoked regularly before 18 or who did not smoke at all until after age 18, this distinction is straightforward. For those who tried smoking before 18 but did not become regular smokers until after age 18 , the distinction is more difficult since their initial decision to try smoking may or may not have led directly to their regular smoking after turning 18. Existing data provide some upper and lower bounds for how to apply the 'principle of insufficient reason' approach. According to the 2014 Surgeon General's report, $77.3 \%$ of persons who ever smoked daily tried their first cigarette before they turned 18 years old, while $47.9 \%$ were daily smokers before age $18 .{ }^{10}$ Research on smoking uptake trajectories shows that many adolescents transition quickly from experimentation to addiction, with variability across individuals due to genetic, social, environmental and cultural factors. ${ }^{19}$ It seems reasonable to consider those who had been smoking for at least a year before turning 18 to be regular smokers by the age of 18 , implying that consumer surplus for those starting before turning 17 should be ignored. This sets a lower bound at the $70.3 \%$ of adult daily smokers who tried their first cigarette before turning 17 . How the remaining $7 \%$ who started sometime between turning 17 and turning 18 should be treated is debatable, but it seems reasonable to assume that those smoking for at least half the year, or perhaps 3 months, could also be considered regular smokers by the time they turned 18. Assuming that initiation among 17 -year-olds is evenly distributed throughout the year, this would imply ignoring $73.8 \%$ of consumer surplus if using a 6-month threshold and $75.5 \%$ if using a 3 -month threshold.

If anything, this understates how much of consumer surplus should be ignored based on early initiation. Specifically, 18 years of age may not be the appropriate cut-off given the trend towards increasing the minimum legal purchase age for tobacco products. Four states (Alabama, Alaska, New Jersey and Utah, USA) and several local governments have raised the minimum purchase age to 19 years. If one uses 19 as the cut-off, the recent data imply that $86.9 \%$ of the consumer surplus should be ignored. Others have gone further, raising the minimum legal purchase age to 21 years, including several Massachusetts townships, Hawaii County, and, effective this July, New York City, while bills to do the same have been introduced in Colorado and Maryland and appear likely in several other states, including Massachusetts, Mississippi, Utah and Washington. Using 21 years of age as the threshold would take at least $91.8 \%$ of the consumer surplus off the table, given the recent data on age at initiation and assuming that anyone smoking for more than 6 months before turning 21 is considered a regular smoker.

For smokers who started smoking after reaching the legal age, it is harder to assume that their initiation decisions are completely irrational. This does not mean that the assumption is 
necessarily wrong, but that the legal status of smoking suggests that society views adults as making rational, informed decisions to start. If these smokers are truly making fully informed, rational decisions, it is unlikely that the initially proposed GWLs would impact their smoking, given that the labels would not be providing new information about the health consequences of smoking (although the negative psychological effects of seeing the graphic images might lead some smokers on the margin to quit). However, new research demonstrates that smokers do not truly fully understand the health consequences of smoking. ${ }^{20}$ Further, the fact that new evidence is continuously emerging about the diseases caused by smoking suggests that it is impossible to say that existing smokers are making fully informed decisions. For example, the 2014 Surgeon General's report for the first time identified smoking as causally linked to colorectal and liver cancer, macular degeneration, tuberculosis, diabetes, erectile dysfunction, rheumatoid arthritis and immune function, while also suggesting that active smoking caused breast and prostate cancer and asthma in adults. ${ }^{10}$ Each of these conclusions postdates planning of the original set of GWLs and hence is not included among them. However, these new findings could be presented in future GWLs.

To the extent that rational smokers change their behaviour in response to information conveyed by GWLs, it is unlikely that this would make them worse off because of the loss of the pleasure they received from smoking decisions made with imperfect, incomplete information. Indeed, to the extent that the labels are effective in moving some smokers to successfully quit-something most want to do and that more than half try to do every year-the reductions in smoking that result should be treated as a benefit rather than a cost that offsets the health benefits that result from quitting. The GWL-prompted decision to quit reflects the smoker's conclusion that he or she derives more utility by not smoking than by smoking. This is consistent with the analysis of Gruber and Mullainathan. ${ }^{17}$

For adult initiators, our consensus is that the larger failure is their inability to quit, even when that is their long-run planwhat we call the self-control problem. In the simplest model, adults would smoke even if the pleasure they derive from smoking is less than the costs they incur if those future costs are excessively discounted, a calculus further complicated by addiction. If smoking is an addiction-related, impulsive behaviour, then GWLs could significantly affect how and whether such impulses are turned into smoking behaviour. The behavioural economics literature has formalised the time inconsistencies that impede smokers' quit attempts in two key theoretical concepts: present bias and projection bias. Present bias is the tendency to systematically overvalue immediate costs and benefits relative to those in the future, leading to impulsivity and self-control problems. ${ }^{21}$ Projection bias is the tendency to underpredict how much a person's preferences will change in the future; that is, smokers may underpredict the degree to which they will value being smoke-free. ${ }^{22}$

The costs of these biases to smokers (and thus the benefits of quitting smoking) have not been fully incorporated into economic analyses of tobacco control regulations, leading to underestimates of the net benefits of quitting and of regulations that promote quitting. In its economic analysis of the impact of warning labels, the FDA includes an estimate of the cost of present bias for smokers. However, the degree of present bias is assumed and not empirically derived, and the costs apply only to 'sophisticated' smokers who are fully aware of their selfcontrol problems and not to 'naïve' smokers who are less than fully aware, even though the literature notes that the costs to naïve consumers are most likely larger. ${ }^{23} 24$ The FDA's analysis excludes the costs of projection bias.

The FDA, in its impact analysis of GWLs, relies on the work of Gruber and Köszegi to calculate the costs of present bias to smokers, ignoring the costs of projection bias. In their 2004 paper, Gruber and Köszegi ${ }^{23}$ calculate an optimal cigarette tax rate of $\$ 5-10$ per pack by assuming a certain degree of present bias; the figures most likely represent an underestimate as they are more than a decade old. In a recent analysis, Levy calculates that adding the effect of projection bias leads to an optimal tax rate of $\$ 8-11$ per pack, ${ }^{25}$ considerably greater than the estimate used in the FDA's analysis. This implies that the consumer surplus 'loss' resulting from the FDA rulemaking is considerably smaller than what the FDA estimated in its final GWL rule.

Finally, as highlighted by Laux, ${ }^{26}$ the importance of peer effects in smoking causes the amount of consumer surplus to be partly determined by societal smoking rates. Consequently, regulations that lead smokers to quit can lead to gains, or 'negative losses', in consumer surplus. While peer effects are particularly important for young people, ${ }^{19}$ growing evidence indicates that they are also important for adults. ${ }^{27}$ How consumer surplus is affected by peer influences largely depends on social norms about smoking. As antismoking norms get stronger, smokers are increasingly marginalised, implying that quitting smoking will enhance an individual's well-being. In the instance of the GWLs, this reflects the fact that decisions to quit smoking are made voluntarily by individuals. Note that peer effects are likely to be especially important among the low-income and less-educated, the populations with higher smoking prevalences.

Given these issues, we conclude that nearly all of the lost pleasure' from tobacco use, as represented by conventionally measured consumer surplus, should not be included as a cost in FDA analyses of the economic impact of its tobacco regulations. The principle of insufficient reason suggests that the vast majority of any consumer surplus loss should be ignored given that most tobacco users become addicted regular users before reaching the legal purchase age. For those who do begin as adults, their imperfect information and self-control problems (and the associated psychological costs), increased consumer surplus from alternative consumption, and the importance of peer effects reflected in strong anti-tobacco norms suggest that regulations that reduce their tobacco use are more likely to be welfare enhancing than not. Indeed, the data strongly suggest that many smokers do not find smoking pleasurable and that they derive little consumer surplus from smoking. Instead, most are struggling with or avoiding the withdrawal they would experience if they were able to stop smoking and break an addiction they regret having ever started, facing psychological costs from being addicted and lacking the self-control to quit.

\section{CONCLUSIONS}

Federal policy requires, and the American public deserves, an assessment of the benefits and costs that will accompany new FDA regulations. To most Americans, including most educated citizens, benefit-cost analysis is something of a black box, a technique that they believe to be reasonably objective, comparing relatively clear-cut benefits with equally straightforward costs. As all economists appreciate, however, benefit-cost analysis often entails as much art as it does science. Complexities in properly identifying, measuring and valuing all appropriately included benefits and costs mean that any two different economists performing benefit-cost analyses of the same proposed regulation may include very different benefits and costs, value them differently, and arrive at different conclusions. 
Benefit-cost analysis of potential FDA tobacco regulations is made even more complicated by the fact that tobacco use is a highly addictive behaviour initiated almost entirely during childhood or adolescence. The conventional assumptions applied in evaluating the welfare effects of regulations are often inappropriate. In particular, the notion that a tobacco user's tobacco-related welfare is measured by conventionally-defined consumer surplus, or even a specific fraction of it, is inconsistent with what science understands about addiction, a process that, as noted, literally rewires the brain. Particularly when that addiction occurs prior to the age of majority-the age at which society deems individuals to be capable of well-informed rational decision-making-we find it inappropriate to measure the area under a demand curve to define welfare. The large majority of tobacco users themselves say that they do not want to continue to use but cannot, or at least have not yet been able to, quit (most having tried multiple times). Those who do eventually quit describe great satisfaction-utility-from having done so. They describe themselves as freed from a burden.

The FDA's analysis of its GWL regulation exhibits several limitations that, we conclude, led the agency to grossly underestimate the net benefits associated with implementation of the regulation. They are as follows:

1. The FDA estimated the impact of Canada's GWLs on its smoking prevalence through an analysis that ignored the actual prices smokers paid for cigarettes. Actual prices during the period at issue were affected significantly by substantial amounts of smuggling, estimated at approximately $25 \%$ of the Canadian market (compared to $6 \%$ in the USA). More recent analyses, taking this and other important variables into consideration, estimate that the GWLs reduced Canada's smoking prevalence by $12.5 \%$ and $12.1-19.6 \%,{ }^{8} 9$ 30 to 50 times more than the FDA's estimate.

2. Even if the lower-bound estimates of impact from the new studies had been employed by the FDA, the estimated benefits would be manyfold larger than the FDA estimated using the FDA's own delineation of the benefits associated with GWL-induced quits.

3. However, as we have described, the FDA has substantially underestimated the benefits, omitting many important benefits such as those associated with reduced secondhand smoke exposure and reductions in the consequences of maternal smoking during pregnancy, as well as reductions in smokers' healthcare expenditures not considered by the FDA (medication costs, home healthcare and other outpatient care).

4. The FDA further underestimates the benefits by inappropriately spreading them uniformly over a period of decades. Thus, the value of health benefits that are realised rapidly, such as reductions in heart disease, is diminished by being discounted heavily over the years.

5. On the cost side of the equation, we disagree with the FDA's inclusion of conventionally measured consumer surplus as a measure of smokers' loss of welfare when, induced by GWLs, they quit smoking. The conventional measure may apply reasonably to a small subset of smokers, but we conclude that that subset represents no more than $20 \%$ of smokers, namely those who (1) started smoking as adults (or started after age 17 and became addicted after age 18), (2) are well (if not fully) informed about the consequences of smoking, (3) have no desire to quit, and of course (4) are somehow induced to quit seemingly against their will by the GWLs. (Their quitting in response to the GWLs would suggest that they value being non-smokers more than continuing to smoke. It is difficult to understand how this represents a loss of welfare.)
The net effect of these limitations in the FDA's analysis is a substantial, even dramatic underestimation of the net benefits of the GWL regulation. We hope that our review will assist the FDA in improving subsequent analyses of the benefits and costs of the GWL regulation. Further, we hope that the many observations we make herein that apply more generally to tobacco product regulation will prove useful to the FDA as it develops benefit-cost analyses of future proposed regulations. Tobacco consumption is the leading cause of preventable premature death in our society, claiming nearly half a million US citizens' lives annually. The FDA is charged with the critical responsibility of regulating the panoply of products that caused this devastation. They should do so in a manner that benefits the public at a reasonable cost. The FDA's proper evaluation of the benefits and costs of proposed regulations is essential to ensure this outcome.

\section{What this paper adds}

- The Food and Drug Administration (FDA) is required to do a regulatory impact analysis assessing the costs and benefits of its tobacco products and other regulations.

- Assessing the costs and benefits of tobacco product regulation raises a number of difficult questions, given that tobacco is unlike other consumer goods and in view of the limited understanding of addiction and the health consequences of tobacco use among potential users, the fact that most initiation occurs during adolescence, and the biases inherent in tobacco use decisions. How to account for these and other factors in the assessment of costs and benefits is controversial.

- This paper provides a critical review of the approach the FDA used in its proposed and final graphic warning label rule, and includes recommendations on how to improve this analysis in ways that account for the differences between tobacco use and consumption of most consumer products.

\begin{abstract}
Author affiliations
${ }^{1}$ Department of Economics, University of Illinois at Chicago, Chicago, Illinois, USA ${ }^{2}$ Department of Health Management \& Policy, University of Michigan, Ann Arbor, Michigan, USA

${ }^{3}$ Department of Economics, Massachusetts Institute of Technology, Cambridge, Massachusetts, USA

${ }^{4}$ Department of Economics, Northeastern State University, Broken Arrow, Oklahoma, USA

${ }^{5}$ Institute for Health \& Aging, University of California, San Francisco, California, USA ${ }^{6}$ Department of Health Care Policy, Harvard University, Cambridge, Massachusetts, USA

${ }^{7}$ Department of Economics, University of Maryland, College Park, Maryland, USA ${ }^{8}$ Health Policy and Management, Yale University, New Haven, Connecticut, USA
\end{abstract}

Acknowledgements The authors thank Angela McGowan, senior programme officer at the Foundation and Jean Steppe for their assistance. This article has previously published on tobacconomics.org.

Contributors FJC and KEW conceptualised this report. KEW obtained funding and organised the meeting that led to the report. All authors provided inputs at this meeting, and JG, DA and WM provided written inputs following the meeting. FJC produced multiple drafts of the report based on the discussions at the meeting and subsequent written inputs. All authors provided input on the draft report and all read and approved the final report.

Funding This work was supported by grant \#71484 from the Robert Wood Johnson Foundation in Princeton, New Jersey.

Competing interests None.

Provenance and peer review Not commissioned; internally peer reviewed. 
Open Access This is an Open Access article distributed in accordance with the Creative Commons Attribution Non Commercial (CC BY-NC 4.0) license, which permits others to distribute, remix, adapt, build upon this work non-commercially, and license their derivative works on different terms, provided the original work is properly cited and the use is non-commercial. See: http://creativecommons.org/ licenses/by-nc/4.0/

\section{REFERENCES}

1 White House. Executive order 12866, regulatory planning and review. Fed Regis 1993;58:51735-44.

2 White House. Executive order 13563, improving regulation and regulatory review. Fed Regis 2011;76:3821-3.

3 Food and Drug Administration. Required warnings for cigarette packages and advertisements, proposed rule. Fed Regis 2010;75:69524-65.

4 Food and Drug Administration. Required warnings for cigarette packages and advertisements, final rule. Fed Regis 2011:76:36628-777.

5 Food and Drug Administration. Deeming tobacco products to be subject to the federal food, drug and cosmetic act, as amended by the family smoking prevention and tobacco control act; regulations on the sale and distribution of tobacco products and required warning statements for tobacco products, proposed rule. Fed Regis 2014;79:23142-207.

6 Ashley EM, Nardinelli C, Lavaty RA. Estimating the benefits of public health policies that reduce harmful consumption. Health Econ Published Online First: 25 February 2014; doi: 10.1002/hec.3040

7 Song AV, Brown P, Glantz SA. When health policy and empirical evidence collide: the case of cigarette package warning labels and economic consumer surplus. Am J Public Health 2014;104:e42-51.

8 Azagba S, Sharaf MF. The effect of graphic cigarette warning labels on smoking behavior: evidence from the Canadian experience. Nicotine Tob Res 2013;15:708-17.

9 Huang J, Chaloupka FJ, Fong GT. Cigarette graphic warning labels and smoking prevalence in Canada: a critical examination and reformulation of the FDA regulatory impact analysis. Tob Control 2014;23(Suppl 1):i7-12.

10 U.S. Department of Health and Human Services. The health consequences of smoking - 50 years of progress. A report of the surgeon general. Atlanta, GA: U.S. Department of Health and Human Services, Centers for Disease Control and Prevention, National Center for Chronic Disease Prevention and Health Promotion, Office on Smoking and Health, 2014.

11 U.S. Department of Health and Human Services. The health consequences of smoking. A report of the surgeon general. Atlanta, GA: U.S. Department of Health and Human Services, Centers for Disease Control and Prevention, National Center for Chronic Disease Prevention and Health Promotion, Office on Smoking and Health, 2004

12 Sloan FA, Osterman J, Picone G, et al. The price of smoking. Cambridge, MA: The MIT Press, 2004.

13 Johnston LD, O'Malley PM, Bachman JG, et al. Monitoring the future national survey results on drug use, 1975-2012: Volume 2, college students and adults ages 19-50. Ann Arbor, MI: Institute for Social Research, The University of Michigan, 2013.

14 Fong GT, Hammond D, Laux FL, et al. The near-universal experience of regret among smokers in four countries: findings from the International Tobacco Control Policy Evaluation Survey. Nicotine Tob Res 2004;6(Suppl 3):S341-51.

15 Centers for Disease Control and Prevention. Quitting smoking among adultsUnited States, 2001-2010. MMWR Morb Mortal Wkly Rep 2011;60:1513-19.

16 Warner KE, Mendez D. Tobacco control policies in developed countries: yesterday, today, and tomorrow. Nicotine Tob Res 2010;12:876-87.

17 Gruber JH, Mullainathan S. Do cigarette taxes make smokers happier? B E J Econom Anal Policy 2005;5:1-45.

18 Arain $\mathrm{M}$, Haque $\mathrm{M}$, Johal $\mathrm{L}$, et al. Maturation of the adolescent brain Neuropsychiatr Dis Treat 2013;2013:449-61.

19 U.S. Department of Health and Human Services. Preventing tobacco use among youth and young adults. A report of the surgeon general. Atlanta, GA: U.S. Department of Health and Human Services, Centers for Disease Control and Prevention, National Center for Chronic Disease Prevention and Health Promotion, Office on Smoking and Health, 2012.

20 Kollath-Cattano CL, Abad-Vivero EN, Thrasher JF, et al. Adult smokers' responses to 'Corrective Statements' regarding tobacco industry deception. Am J Prev Med 2014:47:26-36.

21 Laibson D. Golden eggs and hyperbolic discounting. Q J Econ 1997;112:443-77.

22 Lowenstein G, O'Donoghue T, Rabin M. Projection bias in predicting future utility. Q J Econ 2003;118:1209-48.

23 Gruber JH, Köszegi B. Is addiction rational? Theory and evidence. Q J Econ 2001;116:1261-303.

24 O'Donoghue T, Rabin M. Doing it now or later. Am Econ Rev 1999;89:103-24.

25 Levy M. An empirical analysis of biases in cigarette addiction. Manuscript 2010 http://people.rwj.harvard.edu/ mlevy/cigarettes.pdf

26 Laux F. Addiction as a market failure: using rational addiction results to justify tobacco regulation. J Health Econ 2000;19:421-37.

27 Christakis NA, Fowler JH. The collective dynamics of smoking in a large social network. N Engl J Med 2008;358:2249-58. 